\title{
MEASUREMENT OF INTANGIBLE ASSETS IN RECOVERY AREAS AND OPERATION OF NATURAL RESOURCES
}

\author{
Ioan I. GÂF-DEAC ${ }^{1}$, Cristina Monica VALECA ${ }^{2}$, Elena GURGU ${ }^{3}$, \\ Adrian BĂRBULESCU ${ }^{4}$ \\ ${ }^{l}$ Spiru Haret University, Faculty of Juridical, Political and Administrative \\ Sciences, Bucharest, 24 Berceni Highway, District 4, Bucharest, 030045, \\ Romania, Tel.: +4021.334.44.19, Fax: +4021.334.44.19, \\ Email: editurafmp@gmail.com \\ ${ }^{2}$ University of Pitești, 1 Targul din Vale Str., 110040, Pitești, Argeș County, Tel.: \\ +40348.453.102, Fax: +40348.453.123, Romania; Nuclear Research Institute \\ (ICN), Pitești, 1Campului Str., POB 78, 115400, Mioveni, Argeș County, \\ Romania, Tel.: +40248.21.34.00, Fax: +40248.26.24.49, \\ Email: monica.valeca@nuclear.ro \\ ${ }^{3}$ Spiru Haret University, Faculty of Economic Sciences, Fabricii Street, no. 46G, \\ Bucharest, 030045, Romania, Tel.: +40212.169.793, Fax:+40213.169.793, \\ Email: elenagurgu@yahoo.com \\ ${ }^{4}$ University of Petroșani, 20 Universității Str., 332006, Petroșani, Hunedoara \\ County, Romania, Tel.: +40254.549.010, Fax: +4025.454.349, \\ Email: adi.barbulescu@gmail.com
}

\begin{abstract}
The paper shows that, at the present moment, intangible assets are considered "goods" and, as such, the practice of classical accounting considers intellectual capital in the same category of "goods assimilated/similar to those visible/tangible". From the research it results that the professional literature on measuring knowledge assets/intellectual capital, both in Romania and worldwide, is not large enough and does not provide finite significant, "strong" aggregates regarding the semantic classifications, of content and quality, of the issues in the field. The book titled New Economy between Knowledge and Risk (Ioan I. Gâf-Deac) presents the original systematization and classification of some models and methodologies for measuring knowledge assets, and intellectual capital in socio-economic sciences, and, as such, in this present article, we have resorted to the applied extension of formalizing the measurement of intangible assets in the areas of natural resources'operation and exploitation.
\end{abstract}




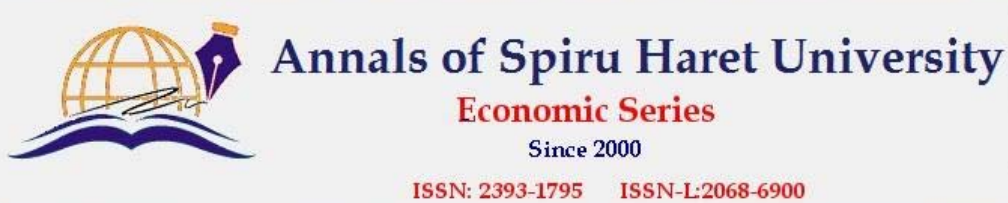

Issue $3 / 2017$

Keywords: exploitation and utilization of natural resources; socioeconomic sciences; intellectual capital; measurement of intangible assets; intellectual capital measurement models; normal logic; gender; culture; management.

JEL Classification: $\mathrm{M}_{11}, \mathrm{O}_{13}$

\section{Introduction}

In order to conceptualize the models of measuring knowledge assets in the intelligent city, we resort to socio-economic science, being necessary the identification of their key elements.

Intangible assets are considered "goods" and, as such, the classical accounting practice takes into account intellectual capital in the same category of "assimilated/ similar to visible" assets also found in the exploitation and capitalization of natural resources.

Malhotra Y. (2004) [7] points out that the model for measuring the frame and the size/quality of knowledge assets has highly varied methodological options, and practice in the field is influenced by methods from economics, accounting, human resources, intellectual property and so on

It is noted that, mainly, the concern for the evaluation of knowledge assets (intellectual capital) in the field of exploitation and capitalization of natural resources as well, with the help of socio-economic sciences, is not sufficiently formalized, comparatively, for example, with the situation that is more concrete at microeconomic level (in firms, organizations, companies, enterprises, etc.). [7]

In particular, concerns about the conceptualization of models in the field are limited, with no significant theoretical or practical impact, especially when it refers to highly structured areas from a technological point of view, such as the field of exploitation and capitalization of natural resources.

Most models of intellectual capital measurement are based on non-financial indicators, but they are not used exclusively or in single procedures, but only associated with financial indicators in concrete economic-productive systems.

We find that frequently, in the field of exploitation and capitalization of natural resources, the key elements of the models of measuring the knowledge assets, the intellectual capital have complementary status in the extraction framework methodologies and methods, which means analysis by removing the non-determinations.

Non-financial indicators take part semi-integrated, non-articulated to the general economic calculation, their share of influencing the appreciations being still insufficient. Therefore, we appreciate that, in fact, the field of exploitation and capitalization 


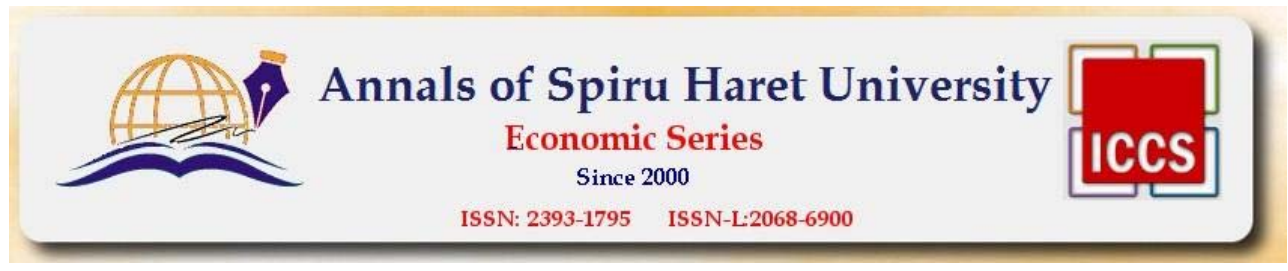

Issue $3 / 2017$

of natural resources practically can be found comparatively more difficult in the new economy, where the measurement is much more advanced as formalization and introduction, functioning actually more significantly and effectively in its incipient phases. However, a conceptualisation gap (a lagging in the theoretical science of the new economy or in socio-economic sciences) still does not allow the generalized representation of the magnitude of the relative effectiveness of the multitude of intangible assets.

In the field of exploitation and capitalization of natural resources we consider useful to integrate aspects derived from the knowledge assets in the strategic and execution analyzes in the productive-economic field, because the specific attributes and influences given by the knowledge specific to each field can lead to their taking into consideration in the quantification/measurement.

Often, the models for measuring knowledge assets/intellectual capital in the field of exploitation and capitalization of natural resources are based on articulated expressions of prominences consisting of: scientific measurements and value judgments.

However, in the field of exploitation and capitalization of natural resources, the interest in searching for different formulas to measure knowledge assets/ intellectual capital is increasing, and programs and highlighting requirements are launched to gain motivation and legitimacy for competitive engagement in the global context.

\section{Measuring the Knowledge Assets/Intellectual Capital in the Field of Exploitation and Capitalization of Natural Resources}

It is noted that in terms of measuring the knowledge assets/intellectual capital in the field of exploitation and capitalization of natural resources, both in Romania and globally, the approach is not wide enough and does not provide significant finite and "strong" aggregates regarding the semantic, content and qualitative classifications of the field problems.

Often, the empirical study of measuring integration and retrieval in the effects of knowledge is used, counting on specific situations and applications, especially at microeconomic level (firms, organizations, etc.) and, in relatively reduced terms, at national or global level.

An attempt in the field is to be found in the EU's Lisbon Strategy (2001) launched for the e-Europe formula for competition reasons with other developed world areas and regions (such as the US). This has appeared in the context in which knowledge is used as a decisive factor in moving social-productive and economic mechanisms to gain competitive advantages, including in the field of exploitation and capitalization of natural resources. 


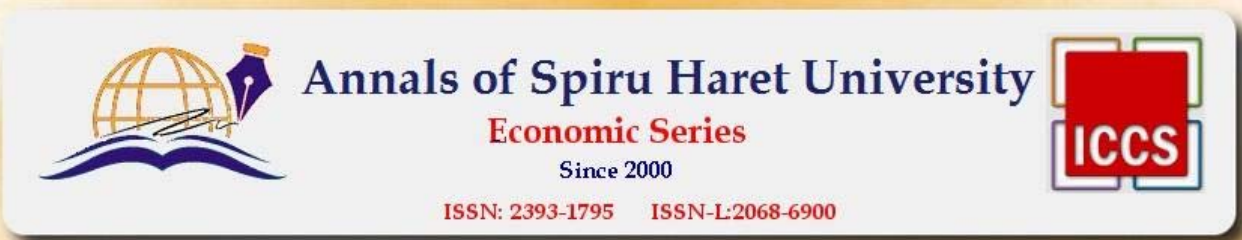

Issue 3/2017

As such, for the extractive sector in Romania, models and methodologies for measuring the knowledge assets/intellectual capital must be systematized in order to use the results to explain the formalization of the new mineral and energetically re-built/clustered economy.

Based on the research carried out, we have categorized the models and methodologies for measuring the knowledge assets/intellectual capital from the socio-economic sciences into groups, as follows [7]:

- Group A - Models based on iterative balance sheets;

- Group B - Models based on methods of direct estimation of the intellectual capital;

- Group C - Models based on estimating the capitalization of the market with intellectual potential;

- Group D - Models based on estimating incomes from knowledge assets.

In the following timeframes (5-10 years), new models/methodologies are expected to appear that will be attached to the above groups, contributing in the filed of exploitation and capitalization of natural resources by completing the measurement/ quantification arsenal in mining knowledge at micro- and macroeconomic levels, respectively at national and zonal/regional/global levels.

The simple conceptual expression of intellectual capital in field of exploitation and capitalization of natural resources is "intangible economic substance".

In extractive productive enterprises there is a combination, most often ambiguous, between the intangible capital (the intellectual one), the human capital, the investment, the instructional one, the individual one, and so on.

The intellectual capital in the field of exploiting and capitalizing natural resources is the support for the affirmation of the industrial intellectual property.

The most significant local areas for intellectual capital are found in information technologies, innovative research, investments that are increasingly operating in the field of exploiting and capitalizing natural resources.

It is still difficult to translate intellectual capital into "shares" (shareholder ownership) within extractive firms, as different interpretations exist (e.g., between "instructions, extractive security rules", etc., and what is left of the "industrial intellectual capital brand", that is what intellectual property signifies).

Intellectual capital in the field of exploiting and capitalizing natural resources must be organized and managed. In some more modern visions, the intellectual capital has in its composition: $a$ ) the human capital (for example, employee's talent); b) the structural capital (non-human information) and c) the relational capital (knowledge in business networks). 


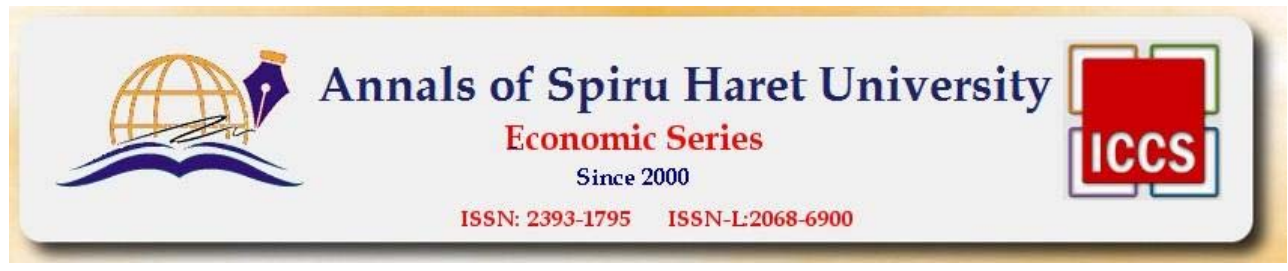

Issue $3 / 2017$

In the context, in the field of exploiting and capitalizing natural resources, the socalled "brand of the industrial intellectual capital" affects the basics of the classical model of the production factors from the micro-economy, as an extractive enterprise measures and expresses the results of its evaluations compared to its total value, considering the quantity and value of the knowledge it holds and operates with.

The contribution of the intellectual capital in the field of exploiting and capitalizing natural resources to the emergence of the new economy is remarkable in the combination that it determines between "individual" and "instructions", as long as it is recognized that "all instructions derive from the individual/individualities", which ultimately formalizes the industrial instructional capital.

At the same time, it is observable that, for the construction and manifestation of the intellectual capital in field of exploiting and capitalizing natural resources, cooperation groups or different systems from the micro-economy specific to the field operate without taking into account the pre-existing social conditions in the extraction enterprises.

However, human capital has the status of implicitly assumed share capital depositary.

In fact, "informal trust", as a manifestation in the human productive activity, should not be neglected.

Presumably, in the field of exploiting and capitalizing natural resources, the combination of the intellectual processes through individual creativity takes place. This type of manifestation can be called "of extractive interoperability".

The role of "trust" cannot be excluded from intellectual work.

The industrial instructional capital is subject to protection, although it is the expression of the individual capital (people, employees) and of the natural capital (resources, ecology).

However, in the field of exploiting and capitalizing natural resources, the emergence of the so-called "biopiracy" is increasingly visible in the new economy, when the human capital, owner of the knowledge capital, is attracted to one place or another through "human colonization" attracts, to be used relational in production and breeding.

In the field of exploiting and capitalizing natural resources, in the new economy, it is appreciated that, in fact, the extractive creativity as a potential process is about to come out of "underestimation", and correspondently "imitation" to cede from the "overestimation" it displays.

It is advanced the ascertainment that the underestimation of creativity and overestimation of imitation in the early $21^{\text {st }}$ century economy in the field of exploiting and capitalizing natural resources is due to the lack of clearer, more accurate, more visible global extractive economic goals. 
Issue 3/2017

For any process, including economical, in the field of exploiting and capitalizing natural resources, in order for it to unreel, a minimal relationship of trust between its elements is necessary.

Paradoxically, the protection of extractive intellectual property is the one which tempers the plenary, free and unrestrained manifestation of creativity's results, in relation to the objectively imposed tendency of increasing novelty in the economy in the field of exploiting and capitalizing natural resources.

According to the "Report to a Knowledge Society", developed by UNESCO in 2005, it results that the information and communication technologies (ICTs) are the physical support of knowledge.

Generalizing the use of this group of technologies (in a distinctive typology) induces changes in the contemporary human society, including in the field of exploiting and capitalizing natural resources, with visible consequences in the economy, determining in fact the emergence of the new economy through: 1) freedom; 2) democracy; 3) informational plurality; 4) a new economic infrastructure, and 5) a new learning and education process.

That is why the need for free knowledge is felt in the field of exploiting and capitalizing natural resources. This is represented by knowingness, which can be reformulated in relation to the needs of the community in the extractive basins, or in their interest. In order to be free, knowledge/knowingness in the field of exploiting and capitalizing natural resources must be accessible.

Therefore, the new mining economy is based on the accessibility of knowledge/knowingness in the socio-economic sciences. Knowledge users in the new economy from the field of exploiting and capitalizing natural resources must be free in order to use work for any purpose, to study the knowledge mechanism, to be able to modify or adapt its content to one's own needs.

Knowledge in the mining sector can be both qualitatively and quantitatively addressed, as it complies with the process of collection, processing, storage, and accumulation through data and information. Knowledge can be considered as a rare resource/characterized by rarity.

Observations can be accumulated, obtaining thus a certain amount of observable information substance. Therefore, in the field of exploiting and capitalizing natural resources, a data, information, and extractive knowledge economy is implicitly subject to modelling.

Knowledge and learning in the economic models provide the conditions for the innovative ownership of activities in the new economy from the field of exploiting and capitalizing natural resources. On the other hand, it is appreciated 38 


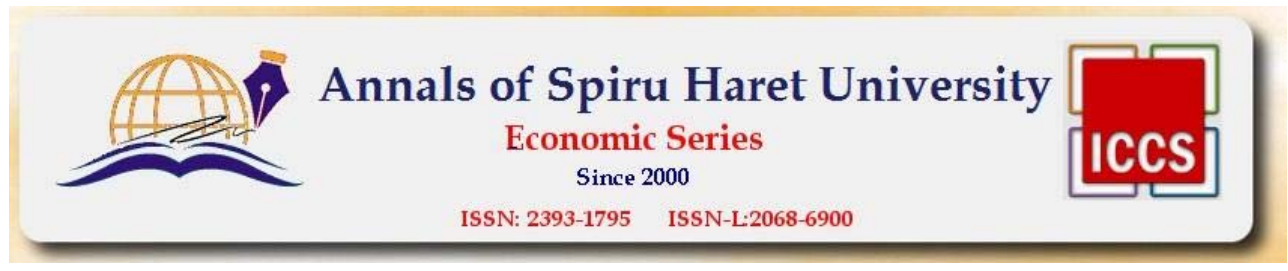

Issue $3 / 2017$

that the organizational structure of the modern extractive enterprise, respectively the structure of its capital, can contribute significantly to providing new ways for the formalization of the innovative productive capacity.

However, for intangible assets, respectively for knowledge in the mining sector, there is a consensus that defines their significant retrieval as representativeness measured in the organizational capital of the enterprise. Therefore, in the field of exploiting and capitalizing natural resources, the measurement, respectively the quantification of the contribution of the organizational capital to the achievement of the ordered values (outputs) proves imperatively current.

Organizational changes and extractive enterprises' reengineering are treated as intangible "consumables" that at most pre-determine/determine the physical growth and that of the role/efficiency of the physical assets.

In the field of exploiting and capitalizing natural resources, there is no real market for intangible assets/capital subject, for example, to some pressures of transformational similarity and results as it happens, for example, with the human capital.

Bontis N. [1] considers that intangible assets, in relation to the issue of their measurement, can be grouped into three categories, as follows:

- intangible assets that can be held and transmitted (sold/purchased). This category includes copyright, trademarks, trade names, and so on;

- intangible assets that can be controlled by the firm (the mining enterprise) but cannot be taken apart (separated, delimited) for alienation;

- intangible assets with a very high degree of difficulty to measure and that cannot be fully controlled/under the control of the firm (the mining company).

The organizational capital in the field of exploiting and capitalizing natural resources, usually in extractive enterprises, is perceived under three aspects: 1) by training of the labour force (highly professional labour force); 2) through the representation of functions/posts and 3) by projecting the extractive work (projected work).

The actional/operational multidimensionality of the extractive enterprise is influenced by the organizational capital, which has to be measured, quantified to deduce its footprint in productive/reproductive evolutions, of distribution and consumption.

By extension, in the field of exploiting and capitalizing natural resources it is necessary the freedom of multiplication and distribution of knowledge, in their entirety, or partial, without restrictions.

"Unacceptable (Wrong)", "Normal" and "Plausible" for the Equal Participation in the Field of Exploiting and Capitalizing Natural Resources

In the complex extractive systems, the dynamics is not correlative or cooperative (available) with respect to the specific knowledge/knowingness. That 

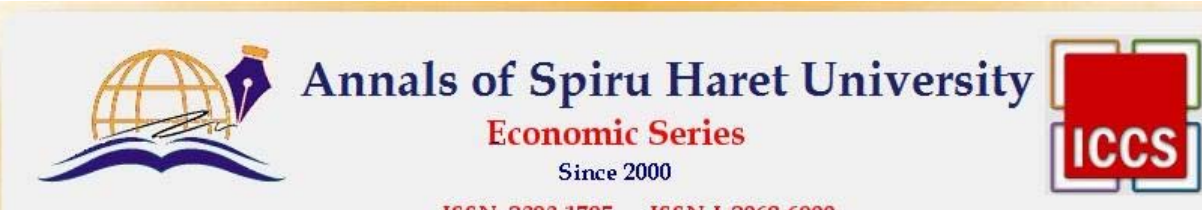

ISSN: 2393-1795 ISSN-L:2068-6900

Issue 3/2017

is why, knowledge in the field of exploiting and capitalizing natural resources is affected by dynamics.

The participation with equal opportunities in the extractive sector is, in our opinion, between reached states of belief/confidence and conventional "incorrect" information, when conflicts arise amid the struggle for the survival of the concepts themselves and their manifestation through tendencies.

Participatory concepts are alive, including the one related to equal opportunities, and self-manifests for appearance, especially in the content and form of the states.

In the intelligent city, in the operational and managerial systems, one can distinguish: a) syntactic judgments and b) semantic judgments.

We appreciate that the probabilistic networks of the subsystems in the field of exploiting and capitalizing natural resources are quantitative, resulting from the above-mentioned judgments and are structured in "base intervals" or "high orders".

Such a situation suggests a certain guarantee for the existence of equal opportunities in the industrial extraction of creators and, at the same time, of the organizational culture consumers.

Taking into consideration the potential distances between the particularities of the mining organizational cultures present in the extractive sector, it is deduced that some qualitative probabilistic calculations lead to propositions expressing the epistemic orders of preferences of those who support and create the framework for decisional formulas in the organization and management of the process of nondifferentiation of equal opportunities in the respective mining area.

Relations between 1) "unacceptable (wrong)," 2) "normal" and 3) "plausible" are emerging, relations that determine possible axiomatic checks regarding the participation with equal opportunities in the field of exploiting and capitalizing natural resources.

The order measure induces quantified/determined consistency and plausibility within the content and form of the cultural states in extractive industries.

Approaching the articulation of equal opportunities' meanings for people in the field of exploiting and capitalizing natural resources, based on the above assertions, can be achieved effectively in the integrated organizational cultural structures.

A set of measured organizational cultural orders, gathered together in the same non-empty set, characterized by an algebra, signifies the formalization of an organizational cultural structure, whether or not in the field of exploiting and capitalizing natural resources.

In such a structure, we meet people (creators, consumers of organizational cultural acts, organizational cultural "lives", but also human and organizational 40 


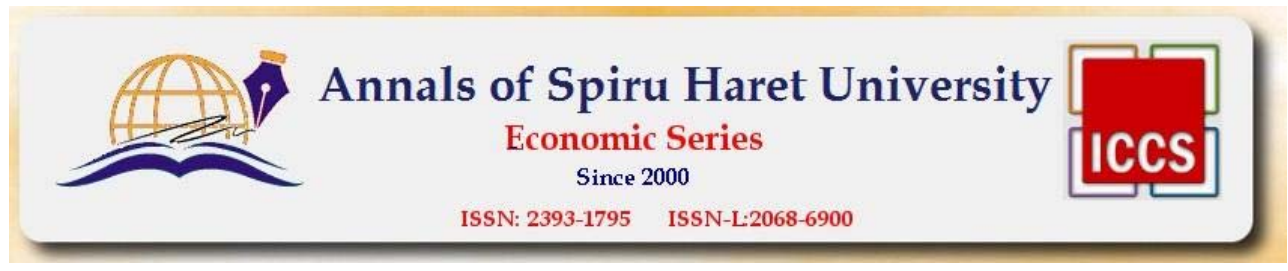

Issue $3 / 2017$

managerial agents) with/on levels of integrated, but not homogenized, confidence/ convictions, specific to the types of judgments in the use of useful substances.

The logical normality for equal opportunities in the field of exploiting and capitalizing natural resources has reflections in the area of pre-logical normality (on the border between real and projection), as well as in the conceptual postlogical area, related to the organizational cultural space gained from the methodic and methodological advance in the field of constructing/developing intelligent culture in an new born natural resource extractive model in present times.

Endogenous/Introspective Modelling of Belief/Trust in People's Equal Access Opportunities in the Field of Exploiting and Capitalizing Natural Resources

Finite reunions of atomized organizational cultural conceptions and attitudes quasi-close the semantic judgments from the new managerial space in the field of exploiting and capitalizing natural resources, being seized the opportunity, everyone's logic, equal chance, of quasi-complete axiomatic characterization of the personal approaches in the large human community of an habitat, for example, the national mining one.

On the other hand, the extractive organizational cultural structures can be considered standardized tools for the intentions of modelling, in an endogenous/ totally introspective manner, the managerial conviction/trust for people's access to the intelligent industrial culture.

The logical normality of an extractive organizational cultural subject is encoded into the finite elements of the managerial logic, as always, in its substance, any subject is latently expandable or available to addition/articulation.

People's usual propositional connectivity to the actions of organizing and managing the integration and to the extractive organizational cultural object always leaves room for the declarative extension, which is the signal of the active normality of those coming from ordinary managerial cultures.

However, it is not always possible to rely on a certain expected level of plausibility of equal opportunities among those who find themselves in the "new field of exploiting and capitalizing natural resources".

Between a) normal and b) plausible, in the iterative reports, the qualitative and relational logic and magnitude is necessary to be identified, i.e. the measure of the extractive cultural semantic interpretations.

What is considered as a conditional error of those who feel the lack of equal opportunities in the field of logic and relational qualitative magnitude is received in a parametric sense and is used as an advance descriptor in the algorithm of managerial cultural integration. 


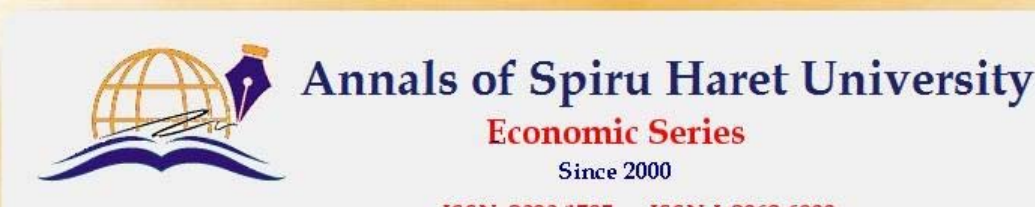

ISSN: 2393-1795 ISSN-L:2068-6900

Issue 3/2017

Thus, ranges of measurement of equal opportunities levels are obtained that predict the new actions in the organizational cultural assimilated states in the field of exploiting and capitalizing natural resources, based on belief-confidence.

Thus, the principle of normality's logic of people's equal access opportunities in the industrial exploitation is shaped as being given by the following articulation: "manager A convinced of the managerial state $\mathrm{S}$ (with conviction in S), resorting to a new conviction $\{\mathrm{NS}\}$, convinces himself that the state $\mathrm{S}$ is the most epistemologically plausible among all the other possible convictions that arise or may arise in the field of exploiting and capitalizing natural resources."

The qualitative measurement of the above interrelation means removing the undetermination between real organizational culture and metaculture in the field of exploiting and capitalizing natural resources.

In essence, we witness to the factual materialization of the participatory approach for equal opportunities in the organizational space, which means that traditional and customary intellectual differentiations between managers and different managerial cultures can be mitigated.

If an L language expresses organizational cultural judgments from managerial integrators from the field of exploiting and capitalizing natural resources, then it is considered that, regardless of the quality and quantity of the expression, an implied, intrinsic satisfaction is advanced associated with the arriving at a conventionally acceptable or unacceptable image for managers' access in the extractive culture, now considered their own, common.

Such a "fulfilment" can be considered the result of the classical organizational cultural satisfaction, due to the judgment issued with the help of the L language.

Different models can be developed for the multitude of elements of "conventional cultural organizational satisfaction accepted in the field of exploiting and capitalizing natural resources", respectively for those of "conventional cultural dissatisfaction accepted in the habitat".

On this occasion, the possibility of iterative ordering and iteration of the measurements/measures aiming the equality of opportunities for managers' access in the field of the sustainable exploiting and capitalizing natural resources is met again.

Thus a degree of "extractive cultural compacting" or "more consolidated cultural density" of the equal access to the New Culture approaches in the field of exploiting and capitalizing natural resources is achieved.

This way, the role of extractive organizational metaculture is actually/reflexively reduced (transferred) in the sphere of conventional culture in the field of exploiting and capitalizing natural resources, as the materialized approaches suggest the operationals from the real extraction system. 


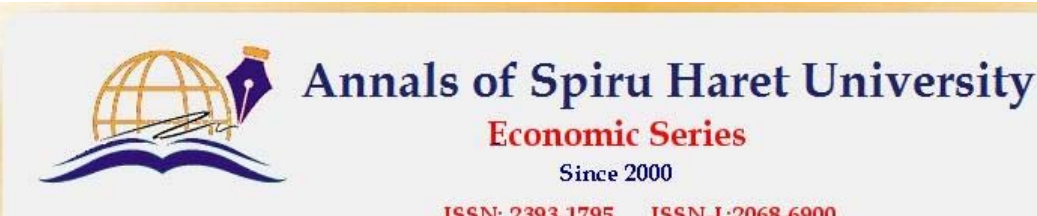

ISSN: 2393-1795 ISSN-L -2068-6900

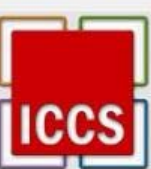

Issue 3/2017

Even if traditional extractive cultural images are used, they become subinstruments of the real extractive cultural mechanism, extended in the field of exploiting and capitalizing natural resources.

It is deduced that on top of the traditional extractive cultural area is predictable the operation with pure extractive metaculture elements, in order to reach a new culture, the sustainable one.

The propositional tautologies suggest rules for implications materialized in schemes and axioms of the participatory approach for each's equality of opportunities within the extractive organizational cultural space.

The schematic and axiomatic arguments support and facilitate cultural connectivity in the field of exploiting and capitalizing natural resources.

The above considerations show that, in essence, the construction of an extractive cultural organizational model must always be based on a logical normality of the equality of access opportunities for managers to the conventional mining culture.

This also comes from the application of axiomatic cultural content imports, related to the general logic, but also from a wide algebra, when, in the field of exploiting and capitalizing natural resources, the declarative cultural organizational density reaches the saturation/satiety.

Practically, we resort to:

1) inducing the convergence of lines (alignments) on which the approaches towards a culture in the field of exploiting and capitalizing natural resources glide;

2) capturing the qualitative probabilistic considerations of cultural objects, processes and phenomena in the extractive sector infrastructure; and

3) suggesting/formalizing the intuitive suitability coming from the decisionmakers and people with equal access in the field of exploiting and capitalizing natural resources.

Managerial thinking in the field of exploiting and capitalizing natural resources must, however, tend to assume "fair, true, considered to be real-fair organizational cultural systems" by restraining them from the conventionally erroneous conditionalities (a process called dis-connectivation).

Conversely, the cultural logical normality conditionalities of equal opportunities in the field of exploiting and capitalizing natural resources cannot exist without their "mirror", respectively without the abnormality conditionalities, considered conventionally erroneous. 
Issue 3/2017

\section{Conclusions}

- The complete axiomatization of extractive organizational cultural approaches is not appropriate for forceful application, as the ambiguity of the integrator's commitment to exploiting and capitalizing natural resources in any extractive cultural situation is not completely eliminated.

- Equal opportunities participation in the field of exploiting and capitalizing natural resources is, in our opinion, between the reached states of belief/confidence and the conventionally "incorrect" information, when conflicts arise amid the struggle for the survival of the concepts themselves and of their manifestation through tendencies.

- The structure of the New extractive organizational Culture can gain compaction, if it is characterized by the logical normality of the equality of opportunities for managers' access to the exploiting and capitalizing natural resources.

- The modalities of evaluating the equality of opportunities in the extractive organizational cultural space presented above are also potentially characteristic to the subsequent, evolutionary, and situational circumstances in the global organizational culture.

- That is why it is at hand to formalize the situational extractive culture, which can benefit from quasi-objective organizational cultural judgments, oriented towards the process of obtaining the plausibility of equal opportunities in the global organizational culture.

- However, the essence of accepting the traditional extractive cultural structures in the structure of the New Culture in the field of exploiting and capitalizing natural resources falls under the involvement in their content of the principle of organizational coherence generating opportunities for equal opportunities in the extractive sector, which has conditioned fundamental significance in the conception regarding the cultural organizational belief/trust based on the logical normality of the general equality of chances.

- The cultural organizational structures in the field of exploiting and capitalizing natural resources can be considered standardized tools for endogenous/ total introspective modelling the access intentions of the managerial conviction/ trust in the extractive sector.

\section{References}

1. Bontis, N., "Assessing Knowledge Assets - a Review of the Models Used to Measure Intellectual Capital," International Journal of Management Review, no. 1/2001. 
2. Boulding, K.E., "The Economics of Knowledge and the Knowledge of Economics," American Economic Review 56, no. 1, 2, 1996.

3. Chivu, L., Evaluarea capitalului uman în România (București: Sorec, 1997).

4. Ciutacu, C., Reformă şi metareformă (București: Expert, 2001).

5. Dzinkowski, R., "The Measurement and Management of Intellectual Capital: An Introduction," Management Acc 78, no. 2, 2000.

6. Edvinsson, L., Sullivan, P., "Developing a Model for Managing Intellectual Capital," European Management Journal 14, no. 4, 1996.

7. Gâf-Deac, I.I., New Economy between knowledge and risk (Deva: Infomin, 2010), 496 p.

8. Gâf-Deac, I.I. (col.), "Relaţii doxastice între creşterea economică şi centralizare," Revista pentru Dezvoltare Bazată pe Cunoaștere - RDBC, Nr. 1, 2015: 9-15.

9. Gâf-Deac, I.I. (col.), "Dezvoltarea durabilă în condiții de instabilitate a civilizației și culturii," Revista pentru Dezvoltare Bazată pe Cunoaștere - RDBC, Nr. 1, 2015: 57-60.

10. Gâf-Deac, I.I. (col.), „Dimensionarea și difuzarea cognitivă a managementului general în condiţiile globalizării," Revista pentru Dezvoltare Bazată pe Cunoaștere - RDBC, Nr. 2, 2015: 79-82.

11. Gâf-Deac, I.I. (col.), "Construction of hyper organizational culture and cultural hyper spaces," Journal of Economics and Knowledge Technologies, No. 3, 2015: 39-42.

12. Gâf-Deac, I.I. (col.), "Highlight matrix of conventional performance levels in higher education," Journal of Economics and Knowledge Technologies, No. 3, 2015: 107-111.

13. Gâf-Deac, I.I. (col.), "Metadagramatic inserting model into database security systems," Journal of Economics and Knowledge Technologies, No. 2, 2015: 18-22.

14. Gâf-Deac, I.I. (col.), "The development trough endogen status of the technical and technological changes," Journal of Economics and Knowledge Technologies, No. 1, 2015: 68-73.

15. Gâf-Deac, I.I., Bazele juridice şi economice ale sistemelor de resurse în noua economie (Deva: Infomin, 2007).

16. Gâf-Deac, I.I., „Metodologie complexă integrată computerizată pentru procesarea dezvoltării structurilor sistemice," Revista Asigurarea şi Promovarea Calităţii, nr. 5, 2002.

17. Gurgu, E., Globalizarea activităţii economice. Realităţi şi tendinţe (Bucureşti: Editura Fundaţiei România de Mâine, 2011), p. 27.

18. Gurgu, E., Economie mondială (Bucureşti: Editura Fundaţiei România de Mâine, 2011), p. 34 .

19. Iliaș, N.T., "Tendinţe de reconsiderare în România a perfecţionării tehnologiilor de exploatare în condiţiile noii clasificări a resurselor/rezervelor," Universitaria Ropet 2003, Inginerie Minieră (Petroşani: Universitas, 2003).

20. Lehr, J.K., Rice, R., "Organizational Measures as a Form of Knowledge Management: A Multitheoretic, Communication-Based Exploration," Journal of the American Sociey for Information Science and Technology, no. 2, 2002.

21. Makishima, S., Pattern Dynamics. A Theory of Self-Organization (Tokyo: Kodansha Scientific, 2001). 
